\title{
UV Light Induced Transformation of 1-Methylnaphthalene in the Presence of Air and Its Implications for Contaminants Research
}

\author{
Yong-Lai Feng ${ }^{1 *}$, Jyoti Prokash Nandy ${ }^{1}$, Yuqing Hou ${ }^{2}$, Francois Breton ${ }^{3}$, Ben Lau ${ }^{3}$, Jianshun Zhang ${ }^{4}$, \\ Jiping Zhu' ${ }^{1}$ \\ ${ }^{1}$ Exposure and Biomonitoring Division, Environmental Heath Centre, Health Canada, Ottawa, Canada; ${ }^{2}$ Department of Chemistry \\ and Biochemistry, Southern Illinois University, Carbondale, USA; ${ }^{3}$ Food Research Division, Bureau of Chemical Safety, Health \\ Canada, Ottawa, Canada; ${ }^{4}$ Building Energy and Environmental Systems Laboratory, Syracuse University, Syracuse, USA. \\ Email: *yong-lai_feng@hc-sc.gc.ca
}

Received July $24^{\text {th }}, 2012$; revised August $23^{\text {rd }}, 2012$; accepted September $25^{\text {th }}, 2012$

\begin{abstract}
Understanding chemical transformations of contaminants and the resulting products is extremely important in devising proper monitoring methods for such contaminants and in assessing potential human exposure to the transformation products in the environment. Ultraviolet (UV) light from the sun can induce various photochemical transformations of contaminants in the environment. Alkylnaphthalenes are light-molecular-weight polycyclic aromatic hydrocarbons (PAHs) which are one of the most widespread organic pollutants present in ambient air as a result of a variety of incomplete combustion sources. In this study, 1-methylnapthalene, a typical example of an alkylnaphthalene, was subjected to UV irradiation to investigate its transformation in the presence and absence of air. Twenty-one products were detected in the reaction mixtures. Some photo-oxidation products were identified, including both ring-opened and ring-retained oxygenated compounds, such as 1-naphthaldehyde, 1-naphthoic acid, 1-naphthalenemethanol and phthalic anhydride. Although dimeric products were observed in the presence of air, more were found in the presence of helium or argon gas, indicating a different photo-oxidation pathway from those commonly observed in other media, such as water. Under just 48 hours of exposure to the UV light in the presence of air, three major products were formed with a production yield of about 10\% each. Compared to 1-methylnapthalene, the UV induced transformation products observed in this study are more volatile, acidic, water soluble or toxic. The formation of these products may significantly change our understanding of the risks assessed solely from the parent compound in contaminants research and supports the inclusion of airborne transformations of the parent compound in risk assessment.
\end{abstract}

Keywords: Transformation Products; 1-Methylnaphthalene; UV Light; Photo-Oxidation; Contaminants Research

\section{Introduction}

Methylnaphthalenes (MNs), dimethylnaphthalenes (DMNs) and ethylnaphthalenes (ENs) are common polycyclic aromatic hydrocarbons (PAHs) emitted into ambient air from a variety of incomplete combustion sources, including diesel engines [1-7], and wood burning [8,9]. These substances are predominantly present in the gas phase [10]. Although air quality can be influenced by these methylnaphthalenes in the gas phase, the reactions with environmental conditions and subsequent transformation products may also be of concern. Sunlight UV, majorly UVA (315 - $400 \mathrm{~nm})$ and UVB (280 - $315 \mathrm{~nm})$, is a common environmental factor in both indoor and

\footnotetext{
"Corresponding author.
}

outdoor. Several studies conducted either in outdoor environments [11-13] or in seawater [14] have indicated that 1-methylnaphthalene is readily photo-oxidized and transformed to secondary pollutants under sunlight UV or simulation UV light. It was also reported that at ambient temperature, dimethylnaphthalenes and ethylnaphthalenes in the gas phase can undergo radical-initiated reactions with hydroxyl $(\mathrm{OH})$ radicals [15], forming dimethylnitronaphthalenes and/or ethylnitronaphthalenes, which have been identified in ambient air samples collected in Southern California [16]. Previously reported atmospheric lifetimes, due to gas-phase reactions with $\mathrm{OH}$ radicals, are about 2 hours for dimethylnaphthalenes and 3 - 4 hours for methylnaphthalenes and ethylnaphthalenes [11]. A recent report from Chan et al. [17] de- 
scribed the formation of secondary organic aerosols from the gas phase photo-oxidation of 1-methylnaphthalene in a chamber study in the presence of nitrogen oxides. Considering that sunlight-UV induced photochemical transformations could be a major transformation pathway and can take place in the gas phase after the volatilization of compounds in the environment, therefore, understanding the molecular level of reactions of airborne 1-methynaphthalene with UV light, is important for describing how the parent chemical transforms to the resulting products and therefore contribute to the secondary pollutants in the environment.

Although numerous studies have focused on photooxidation of alkylnaphthalenes in the presence of oxygen, the UV induced transformations of alkylnaphthalenes in various reaction conditions, such as in the presence of various gases, in contrast, have not yet been systematically investigated and compared. In the presence of an inert gas such as helium or argon gas, the transformation process is thought to be a photolysis process due to a lack of oxygen in the system. In this study, degradation of 1-methylnaphthalene and formation of transformation products under various reaction conditions, including in the presence of dry or humid air, were systematically investigated. The degradation rate of 1-methylnaphalene was also investigated to evaluate the contributions of UV exposure in the presence of air to the formation of oxygenated transformation products. The implications of the transformation products on air quality and the environment were also discussed.

\section{Materials and Methods}

\subsection{Chemicals and Preparation of Solutions}

1-Methylnaphthalene (95\%), 1-naphthaldehyde (95\%), 1-naphthalenemethanol (98\%), 1-naphthoic acid (96\%), 1-naphthaleneacetic acid (98\%), 2-naphthaleneacetic acid
(99\%), phthalic acid (99.5+\%), phthalic anhydride (99+\%), 2,2'-dimethyl 1,1'-biphenyl (Aldrich compound number T206571), and 2,2'-dimethyl-1,1'-binaphthalene (Aldrich compound number T330272) were purchased from Sigma-Aldrich Canada (Oakville, Ontario, Canada). Hexane (99.98\%), methanol (99.9\%) and dichloromethane $(99.96 \%)$ were purchased from Omnisolv (Swedesboro, NJ, USA).Solutions of 1-methylnaphalene and other standards were prepared by dissolving them inhexane to make $1 \mathrm{mg} / \mathrm{mL}$ stock solutions. The working solutions were prepared by diluting the stock solutions to certain concentrations with hexane.

\subsection{UV Photo-Oxidation of 1-Methylnaphthalene}

The photo-oxidation experiments were carried out in a cylindrical quartz chamber. The chamber was fitted with a Teflon air-lock at both ends, one end was further screwed with a septum thread cap (Figure 1). It was determined that 1-methylnaphthalene was completely adsorbed on the inner surface of the quartz reaction chamber $(\sim 120 \mathrm{cc})$. In order to prevent the adsorption, the surface of a new quartz chamber was deactivated prior to the experiment with a solution of $7 \%$ aqueous ammonium bifluoride for 5 minutes followed by deionized water, then methanol, and dried with zero air. The prewashed and dried quartz chamber was then flushed with dry, clean air, humid air (100\% humidity), helium, or argon gas, depending on the desired experiment, for 5 minutes prior to the introduction of the testing chemical. The two air-lock valves were then closed to ensure the chamber was completely filled with the desired gas. 5.0 $\mu \mathrm{L}$ of neat 1-methylnaphthalene was injected to the centre of the chamber's inner bottom wall through the septum with a specifically designed long-needle syringe. The chamber was placed into an apparatus for 30 minutes

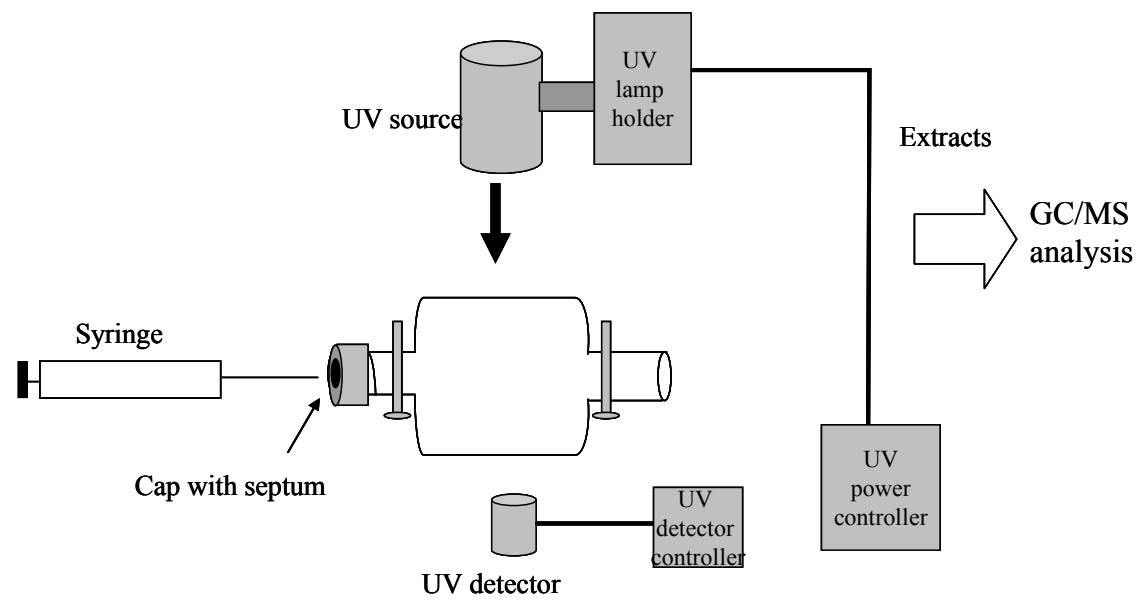

Figure 1. Schematic photo-oxidation system. 
to allow the 1-methylnaphthalene to be naturally evaporated in the chamber. The UV lamp (UV A + B) was then turned on, and the time was recorded. The strength of the UV radiation was set at $26 \mathrm{~mW} \cdot \mathrm{cm}^{-2}$. An identical chamber loaded with same amount of 1-methylnaphthalene in the same way was wrapped with aluminium foil to block any light as the dark control. After a fixed time of exposure, the UV lamp was turned off. Both chambers were rinsed twice with $2.5 \mathrm{~mL}$ of hexane, twice with 2.5 $\mathrm{mL}$ of dichloromethane, and twice with $2.5 \mathrm{~mL}$ of methanol, in sequence. The rinses of solvents were combined and stored at $4^{\circ} \mathrm{C}$ for GC/MS analysis.

\subsection{GC/MS Analysis}

An Agilent GC/MS system (6890N GC and 5973 MSD, Agilent Technologies (Canada) Inc., Mississauga, Ontario) was used for both measuring the degradation of 1-methylnaphthalene and identifying reaction products. A DB-5MS GC column $(30 \mathrm{~m} \times 0.25 \mathrm{~mm}$ i.d. $\times 0.25 \mu \mathrm{m}$ film thickness, J \& W Scientific, Folsom, USA) was used. The injection port temperature was $280^{\circ} \mathrm{C}$, the oven temperature was set $45^{\circ} \mathrm{C}$ for 5 minutes, increased to $210^{\circ} \mathrm{C}$ at $15^{\circ} \mathrm{C} / \mathrm{min}$; to $270^{\circ} \mathrm{C}$ at $8^{\circ} \mathrm{C} / \mathrm{min}$; to $310^{\circ} \mathrm{C}$ at $30^{\circ} \mathrm{C} / \mathrm{min}$, and then kept at this temperature for $25 \mathrm{~min}-$ utes. The MSD was operated in full scan mode with a scan range of $30-700 \mathrm{~m} / \mathrm{z}$. The peaks were also analyzed with high resolution mass spectrometer. A COC inlet with track over mode for the temperature was used in coupling with the Waters Autospec Premier double focusing magnetic sector instrument. The magnet scan in $\mathrm{EI}+$ mode was from 60 to $450 \mathrm{~m} / \mathrm{z}$ with parameters: 5000 resolution(at $5 \%$ peak height), $0.5 \mathrm{~s} /$ decadescan time, $0.2 \mathrm{~s}$ interscan time and $0.64 \mathrm{~s}$ total cycle time.

\section{Results and Discussion}

\subsection{The Photo-Oxidation of 1-Methylnaphthalene in Air}

When the chamber containing 1-methylnaphthalene was exposed to UV light in a clean dry air environment, the photo-reaction process was observed visually by the appearance of a light brown colour on the entire internal wall of the quartz chamber. The same colour was also observed on the bottom wall of the chamber, where the starting material was initially placed, indicating that the starting material might not be completely evaporated. The multiple peaks in the total ion chromatogram (TIC) of the GC/MS showed many potential photo-oxidation transformation products in the extracted reaction mixture (Figure 2(a) and 3(a)). Information on those peaks has been summarized in Table 1. Among them, peak 2 was the starting material, 1-methylnaphthalene (Figure 2(a)).
The three most abundant products represented by peaks 7 , 8, and 10 in Figure 1(a) were identified as 1-naphthaldehyde, 1-hydroxymethylnaphthalene (also named 1-naphthalenemethanol), and naphthoic acid, respectively, by comparing their MS spectra and gas chromatographic retention indices with those of authentic reference compounds. The identification of peak 1 was confirmed by comparing the retention time on the chromatogram with the reference standard for phthalic anhydride.

The identification of peak 9 proved to be challenging. That peak was further analyzed with high resolution mass spectrometry and the spectrum indicated a molecular mass of 186.0681 with a formula of $\mathrm{C}_{12} \mathrm{H}_{10} \mathrm{O}_{2}$, its mass spectrum was similar to either 2-naphthaleneacetic acid or 1-naphthaleneacetic acid according to the NIST library (Figure 2(b)). The difference of 28 mass units between the parent peak at $\mathrm{m} / \mathrm{z} 186$ and that at $\mathrm{m} / \mathrm{z} 158$ indicated the loss of a carbonyl group (Table 1). The difference of 17 mass units from m/z 158 to m/z 141 suggested the loss of a hydroxyl group. Additionally, it was suggested that there had been a loss of an ethyl group and a methyl group from a benzene ring as a result of the difference of 26 mass units from m/z 141 to m/z 115 and the difference of 14 mass units from m/z 129 to $\mathrm{m} / \mathrm{z} 115$, respectively. Although the mass spectrum was identical to either of 1- or 2-naphtaleneacetic acid reference standards, neither of the two corresponding standards matched the retention time. Nor was the retention time of 2-methyl-1-naphthoic acid or 4-methyl-1-naphthoic acid. The other possible structure for peak 9 could be naphthalenic acid methyl ester; this has yet to be confirmed.

The mass spectra of peak 4 and peak 5 matched the spectra of 3-methyl-1 $(3 \mathrm{H})$-isobenzofuranone and 3, Xdimethyl-1(3H)-isobenzofuranone ( $\mathrm{X}$ denoting the unknown position of the second methyl group), respectively in the NIST library. The two chemicals were previously reported in the photo-oxidation of 1-methylnaphthalene in seawater [14].

A recent study revealed that the photo-transformation of naphthalene in atmospheric conditions under UV light resulted in the formation of two groups of products: ring-opened products and ring-retained products [17]. Among those ring-opened products, (E)-3-(2-acetylphenyl)acrylaldehyde was identified through the transformation of methylnaphthanyl peroxy radical with oxygen molecules and $\mathrm{NO}$ or $\mathrm{RO}_{2}$ radicals [17]. The mass spectrum of peak 11 (Figure 2(c)) was found to match that of (E)-3-(2-acetylphenyl)acrylaldehyde reported by Chan et al. [17]. In addition, the difference of 29 mass units from the parent peak at $\mathrm{m} / \mathrm{z} 174$ to $\mathrm{m} / \mathrm{z} 145$ indicated the loss of an ethyl group (Table 1), and the loss of 30 mass units from m/z 145 to $\mathrm{m} / \mathrm{z} 115$ might suggest a 

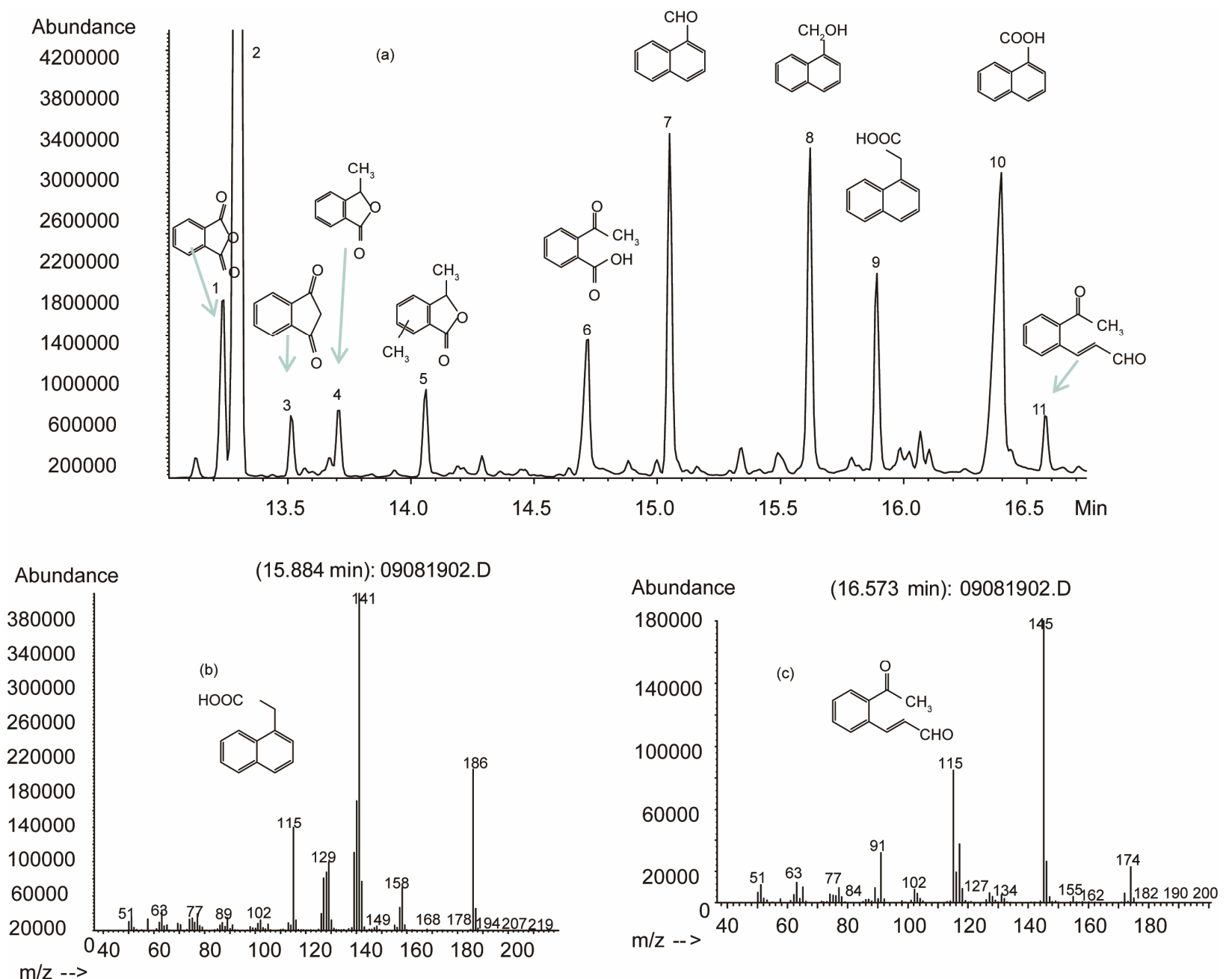

Figure 2. (a): Total ion chromatogram of reaction extracts of 1-methylnaphthalene (retention time from 13 to 17 minutes). UV $(A+B)$ light strength: $26 \mathrm{~mW} \cdot \mathrm{cm}^{-2}$, exposure time: 70 hours. Identification of peaks: 1: phthalic anhydride; 2 : 1-methylnaphthalene; 3: tentatively 1,3-Indandione; 4: tentatively3-methyl-1(3H)-isobenzofuranone; 5: tentatively 3,X-dimethyl-1(3H)-isobenzofuranone; 6: tentatively 2-acetylbenzoic acid; 7: 1-naphthaldehyde; 8: 1-1-naphthalenemethanol; 9: unidentified unknown compound; 10: naphthoic acid; 11: tentatively(E)-3-(2-acetylphenyl)acrylaldehyde; (b): EI mass spectrum peak 9; (c): EI mass spectrum peak 11.

hydroxymethyl group. Moreover, this molecular weight of 174 equals to the sum of 1-methylnaphthalene and two oxygen atoms. Therefore, it would be reasonable to assign this compound as (E)-3-(2-acetylphenyl)acrylaldehyde.

So far, we have discussed identification of peaks eluted between 13 and 17 minutes. Additional peaks (peaks 12 to 22) were also observed in the late elution times after 24 minutes (Figure 3(a)), indicating that these peaks represent compounds with higher molecular weights and which have not yet been reported in previous studies. Information of these peaks is listed in Table 2. Among the peaks in this period, the peak 14 provided a molecular m/z 282.1409 with formula of $\mathrm{C}_{22} \mathrm{H}_{18}$ is exactly equal to the sum of two 1-methylnaphthalene molecules minus two hydrogen atoms. The difference of 141 mass units between the parent peak $\mathrm{m} / \mathrm{z} 282$ and $\mathrm{m} / \mathrm{z}$ 141 indicates the likely loss of a methylnaphthalene group. The difference of 15 mass units each from the parent peak m/z 282 to $\mathrm{m} / \mathrm{z} 267$ and from m/z 267 to $\mathrm{m} / \mathrm{z}$ 252 suggested consecutive losses of a methyl group. Additionally, the loss pattern from $\mathrm{m} / \mathrm{z} 141$ to $\mathrm{m} / \mathrm{z} 115$, then to $\mathrm{m} / \mathrm{z} 77$ and further to $\mathrm{m} / \mathrm{z} 63$ and $\mathrm{m} / \mathrm{z} 51$ followed that of 1-methylnaphthalene, which indicated that it was a dimeric product according to the NIST library. This result indicated that the photo-oxidation mechanism of 1-methylnaphthalene in the dry air environment under UV light might be different from those aforementioned. Relative mass abundances for the rest of the peaks from peak 15 to 22 are outlined in Table 2. All peaks in this 

Its Implications for Contaminants Research

Table 1. Products and proposed structures.

\begin{tabular}{|c|c|c|c|c|c|c|}
\hline Peak $\neq$ & $\mathrm{RT}(\min )$ & Name & M.W. $(\mathrm{m} / \mathrm{z}(+))$ formula & MS spectrum m/z (abundance, $\%)^{\mathrm{e}}$ & Boiling point $\left({ }^{\circ} \mathrm{C}\right)$ & Vapor pressure \\
\hline 1 & 13.234 & $\begin{array}{l}\text { Phthalic anhydride } \\
\text { (isobenzofuran-1,3-dione) }^{\mathrm{a}}\end{array}$ & $\begin{array}{l}148.016 \\
\mathrm{C}_{8} \mathrm{H}_{4} \mathrm{O}_{3}\end{array}$ & $\begin{array}{l}148(\mathbf{2 1}) \\
104(\mathbf{1 0 0}) \\
76(\mathbf{7 9}) \\
50(\mathbf{3 5})\end{array}$ & 295 & \\
\hline 2 & 13.292 & 1-methylnaphthalene ${ }^{a}$ & $\begin{array}{c}142.0783 \\
\mathrm{C}_{11} \mathrm{H}_{10}\end{array}$ & $\begin{array}{l}142(\mathbf{1 0 0}) \\
115(\mathbf{3 2}) \\
89(\mathbf{4}) \\
63(5)\end{array}$ & $240-243$ & 4.91 \\
\hline 3 & 13.512 & $\begin{array}{c}\text { 1,3-indandione } \\
(1 \mathrm{H} \text {-indene-1,3(2H)-dione })^{\mathrm{b}}\end{array}$ & $\begin{array}{c}146.0368 \\
\mathrm{C}_{9} \mathrm{H}_{6} \mathrm{O}_{2}\end{array}$ & $\begin{array}{l}146(\mathbf{1 0 0}) \\
118(\mathbf{1 6}) \\
104(\mathbf{5 1}) \\
90(\mathbf{3 3}) \\
76(\mathbf{4 9}) \\
63(\mathbf{9}) \\
50(\mathbf{2 0})\end{array}$ & & \\
\hline 4 & 13.710 & $\begin{array}{c}\text { 3-methyl } \\
\text { isobenzofuran-1(3H)-one }\end{array}$ & $\begin{array}{c}148.0524 \\
\mathrm{C}_{9} \mathrm{H}_{8} \mathrm{O}_{2} \\
\mathrm{C}_{10} \mathrm{H}_{12} \mathrm{O}\end{array}$ & $\begin{array}{l}148(\mathbf{2 1}) \\
133(\mathbf{6 9}) \\
105(\mathbf{1 0 0}) \\
77(\mathbf{3 4}) \\
51(\mathbf{1 4})\end{array}$ & $\mathrm{n} / \mathrm{a}$ & $\mathrm{n} / \mathrm{a}$ \\
\hline 5 & 14.061 & $\begin{array}{c}\text { Dimethyl-1(3H)- } \\
\text { isobenzofuranone } \\
(1,3 \text {-isobenzofurandione, } \\
\text { 4-methyl- })^{\mathrm{b}}\end{array}$ & $\begin{array}{c}162.0317 \\
\mathrm{C}_{9} \mathrm{H}_{6} \mathrm{O}_{3}\end{array}$ & $\begin{array}{l}162(\mathbf{1 0 0}) \\
147(\mathbf{3 7}) \\
134(\mathbf{4 4}) \\
118(81) \\
90(\mathbf{1 0 0}) \\
63(\mathbf{4 5}) \\
51(\mathbf{1 0})\end{array}$ & $\mathrm{n} / \mathrm{a}$ & $\mathrm{n} / \mathrm{a}$ \\
\hline 6 & 14.713 & 2-acetylbenzoic acid ${ }^{\mathrm{b}}$ & $\begin{array}{c}164.0473 \\
\mathrm{C}_{9} \mathrm{H}_{8} \mathrm{O}_{3}\end{array}$ & $\begin{array}{l}164(\mathbf{1}) \\
149(\mathbf{1 0 0}) \\
121(\mathbf{8}) \\
105(\mathbf{1 6}) \\
93(\mathbf{9}) \\
77(\mathbf{1 1}) \\
65(\mathbf{1 1}) \\
50(\mathbf{8})\end{array}$ & 372 & $0 \mathrm{mmHg}$ at $25^{\circ} \mathrm{C}$ \\
\hline 7 & 15.050 & 1-naphthadehyde ${ }^{a}$ & $\begin{array}{c}156.0575 \\
\mathrm{C}_{11} \mathrm{H}_{8} \mathrm{O}\end{array}$ & $\begin{array}{l}156(\mathbf{1 0 0}) \\
128(\mathbf{9 1}) \\
101(\mathbf{9}) \\
77(\mathbf{1 3}) \\
63(\mathbf{1 1}) \\
51(\mathbf{1 0})\end{array}$ & $160-161$ & $>1$ (vs air) \\
\hline 8 & 15.621 & 1-hydroxymethylnaphthalene ${ }^{a}$ & $\begin{array}{l}158.0732 \\
\mathrm{C}_{11} \mathrm{H}_{10} \mathrm{O}\end{array}$ & $\begin{array}{l}158(\mathbf{5 2}) \\
141(\mathbf{1 5}) \\
129(\mathbf{1 0 0}) \\
115(\mathbf{1 2})\end{array}$ & $\begin{array}{l}303.6^{\circ} \mathrm{C} \text { at } \\
760 \mathrm{mmHg}\end{array}$ & $\begin{array}{l}0.000404 \mathrm{mmHg} \\
\text { at } 25^{\circ} \mathrm{C}\end{array}$ \\
\hline 9 & 15.892 & $\mathrm{x}$-naphthaleneacetic acid ${ }^{\mathrm{b}}$ & $\begin{array}{l}186.0681 \\
\mathrm{C}_{12} \mathrm{H}_{10} \mathrm{O}_{2}\end{array}$ & $\begin{array}{l}186(\mathbf{5 0}) \\
158(\mathbf{1 9}) \\
141(\mathbf{1 0 0}) \\
129(\mathbf{2 3}) \\
115(\mathbf{3 0})\end{array}$ & $\mathrm{n} / \mathrm{a}$ & $\mathrm{n} / \mathrm{a}$ \\
\hline 10 & 16.382 & Naphthoic acid ${ }^{\mathrm{a}}$ & $\begin{array}{l}172.0524 \\
\mathrm{C}_{11} \mathrm{H}_{8} \mathrm{O}_{2}\end{array}$ & $\begin{array}{l}172(\mathbf{1 0 0}) \\
155(\mathbf{5 6}) \\
127(\mathbf{6 6}) \\
115(\mathbf{1 4}) \\
101(\mathbf{6}) \\
77(\mathbf{1 0}) \\
63(\mathbf{1 0}) \\
51(\mathbf{5})\end{array}$ & 300 & $\mathrm{n} / \mathrm{a}$ \\
\hline
\end{tabular}


Continued

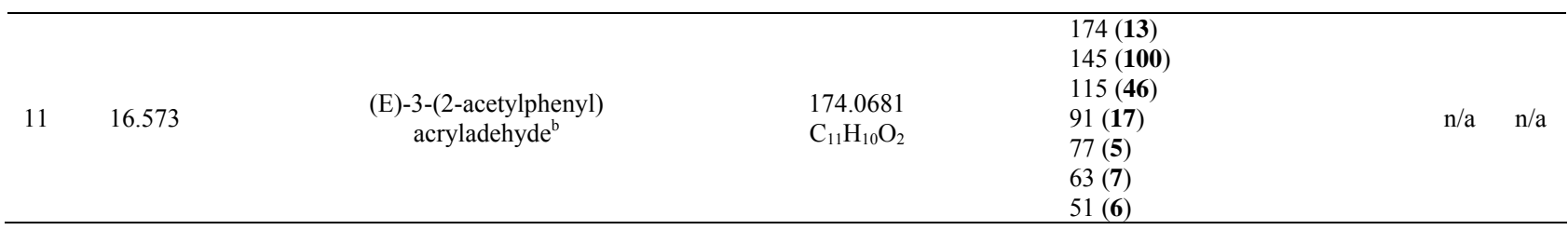

${ }^{\mathrm{a}}$ Identified by the corresponding reference standard; ${ }^{\mathrm{b}}$ Proposed according to NIST library analysis; ${ }^{\mathrm{c}}$ Proposed according to the Mass spectrum; ${ }^{\mathrm{d}}$ No suggestions; ${ }^{\mathrm{e}}$ Relative abundance.
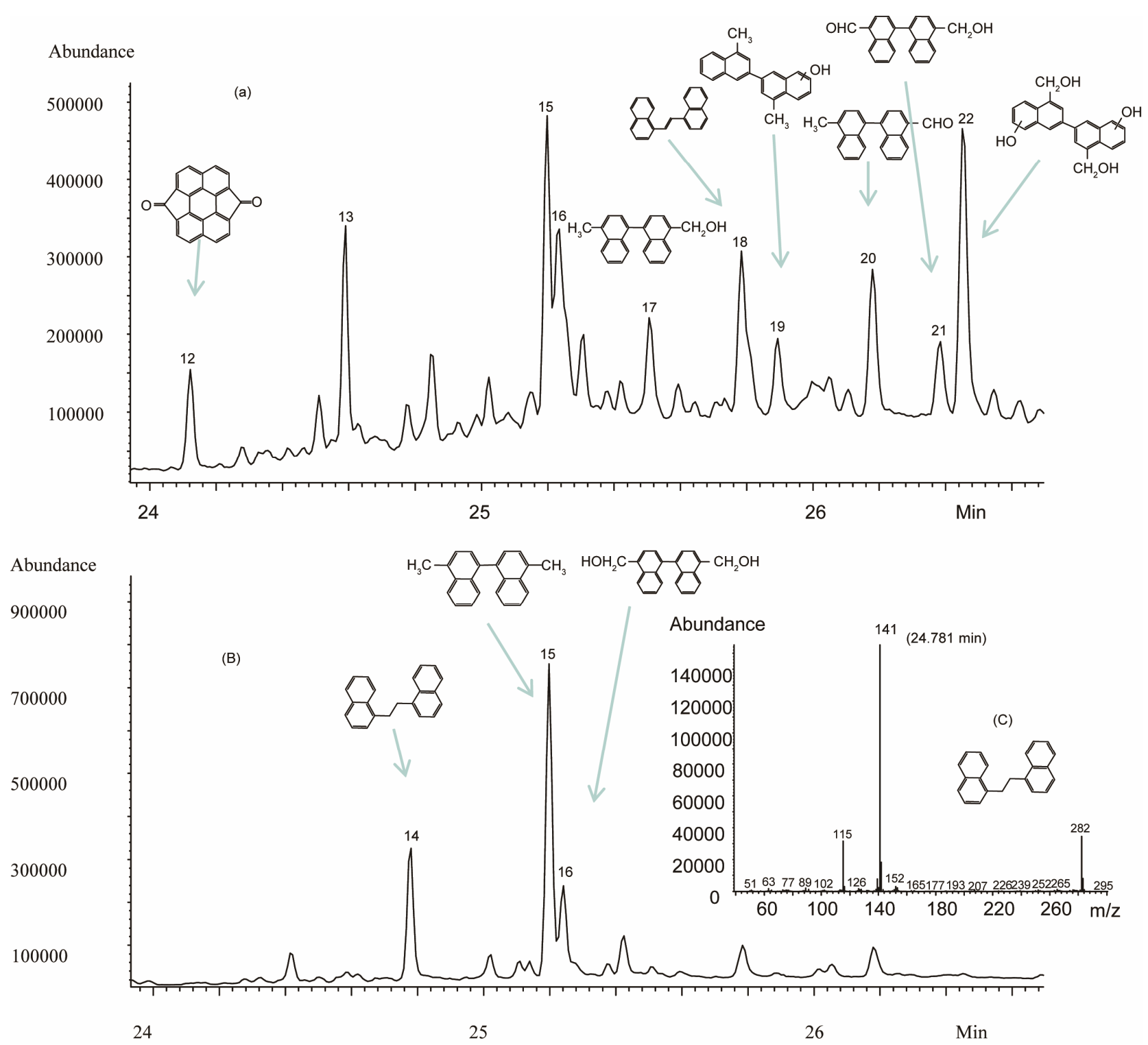

Figure 3. Total ion chromatogram of reaction extracts of 1-methylnaphthalene and possible structures of peaks in the retention time range of 24 to 27 minutes. UV (A + B) light strength: $26 \mathrm{~mW} \cdot \mathrm{cm}^{-2}$, exposure time: 72 hours. (a) Air environment; (b) Inert gas environment; (c) EI mass spectrum of peak 14.

retention time range have not been identified due to the complexity of peaks. However, as their molecular weights are all over 282 and the loss of 141 mass units was indicated in all of their mass spectra, they could be assumed to be all from further photo-oxidation of dimers under UV irradiation in the presence of air. Nevertheless, the compounds represented by peaks 12 to 22 have demonstrated the complexity of the photo-oxidation of 

Its Implications for Contaminants Research

Table 2. Possible dimeric products and proposed structures.

\begin{tabular}{|c|c|c|c|c|c|c|}
\hline Peak \# & $\mathrm{RT}(\min )$ & Name & $\begin{array}{l}\text { M.W. }(\mathrm{m} / \mathrm{z}(+)) \\
\quad \text { formula }\end{array}$ & $\begin{array}{l}\text { MS spectrum } \mathrm{m} / \mathrm{z} \\
{\text { (abundance, } \%)^{\mathrm{e}}}^{\mathrm{e}}\end{array}$ & $\begin{array}{l}\text { Boiling point } \\
\qquad\left({ }^{\circ} \mathrm{C}\right)\end{array}$ & $\begin{array}{l}\text { Vapor } \\
\text { pressure }\end{array}$ \\
\hline 12 & 24.122 & $\begin{array}{l}\text { dicyclopenta[ghi,pqr] } \\
\text { perylene-1,6-dione }^{\mathrm{c}}\end{array}$ & $\begin{array}{c}304.0524 \\
\mathrm{C}_{22} \mathrm{H}_{8} \mathrm{O}_{2}\end{array}$ & $\begin{array}{c}304(\mathbf{3 8}) \\
245(\mathbf{3}) \\
147(\mathbf{1 0 0}) \\
128(\mathbf{1 1}) \\
115(\mathbf{2 5}) \\
105(\mathbf{9}) \\
91(\mathbf{1 7})\end{array}$ & $\mathrm{n} / \mathrm{a}$ & $\mathrm{n} / \mathrm{a}$ \\
\hline 13 & 24.583 & $\mathrm{~N} / \mathrm{A}^{\mathrm{d}}$ & $\begin{array}{c}304.0524 \\
\mathrm{C}_{22} \mathrm{H}_{8} \mathrm{O}_{2}\end{array}$ & $\begin{array}{c}304(\mathbf{4}) \\
148(\mathbf{1 0 0}) \\
129(\mathbf{8}) \\
115(\mathbf{2 5}) \\
105(\mathbf{3 6}) \\
91(\mathbf{1 0}) \\
76(\mathbf{6})\end{array}$ & $\mathrm{n} / \mathrm{a}$ & $\mathrm{n} / \mathrm{a}$ \\
\hline 14 & 24.781 & $\begin{array}{l}1,1^{\prime} \text { '-(1,2-ethandiyl) } \\
\text { bis-naphthalene }{ }^{\mathrm{b}}\end{array}$ & $\begin{array}{c}282.1409 \\
\mathrm{C}_{22} \mathrm{H}_{18}\end{array}$ & $\begin{array}{c}282(\mathbf{2 2}) \\
141(\mathbf{1 0 0}) \\
115(\mathbf{2 0})\end{array}$ & 361 & \\
\hline 15 & 25.198 & $\begin{array}{l}\text { 4,4'-dimethyl-1, } \\
\text { 1'-binaphthylene }\end{array}$ & $\begin{array}{c}282.1409 \\
\mathrm{C}_{22} \mathrm{H}_{18}\end{array}$ & $\begin{array}{c}282(\mathbf{9 3}) \\
267(\mathbf{1 0 0}) \\
252(\mathbf{2 8}) \\
153(\mathbf{8}) \\
141(\mathbf{1 6}) \\
126(\mathbf{1 1}) \\
115(\mathbf{1 4})\end{array}$ & $\mathrm{n} / \mathrm{a}$ & $\mathrm{n} / \mathrm{a}$ \\
\hline 16 & 25.235 & $\begin{array}{l}\text { 1,1'-binaphthalene]-4, } \\
\text { 4'-diyldimethanol }\end{array}$ & $\begin{array}{c}314.115 \\
\mathrm{C}_{22} \mathrm{H}_{18} \mathrm{O}_{2}\end{array}$ & $\begin{array}{c}314(\mathbf{1 1}) \\
282(\mathbf{1 8}) \\
267(\mathbf{1 5}) \\
215(\mathbf{1 0}) \\
141(\mathbf{1 0 0}) \\
115(\mathbf{4 4}) \\
91(\mathbf{9})\end{array}$ & $\mathrm{n} / \mathrm{a}$ & $\mathrm{n} / \mathrm{a}$ \\
\hline 17 & 25.506 & $\begin{array}{l}\text { (4'-methyl- } \\
{\left[1,1^{\prime} \text {-binaphthalen }\right]} \\
-4 \text {-yl)methanol }\end{array}$ & $\begin{array}{l}298.1358 \\
\mathrm{C}_{22} \mathrm{H}_{18} \mathrm{O}\end{array}$ & $\begin{array}{c}298(\mathbf{1 3}) \\
157(\mathbf{1 2}) \\
142(\mathbf{1 0 0}) \\
129(\mathbf{1 8}) \\
115(\mathbf{2 5})\end{array}$ & $\mathrm{n} / \mathrm{a}$ & $\mathrm{n} / \mathrm{a}$ \\
\hline 18 & 25.791 & $\begin{array}{l}\text { (E)-1,2-di } \\
\text { (naphthalen-1-yl)ethane }\end{array}$ & $\begin{array}{c}280.1252 \\
\mathrm{C}_{22} \mathrm{H}_{16}\end{array}$ & $\begin{array}{c}280(\mathbf{5}) \\
157(\mathbf{3 8}) \\
142(\mathbf{1 0 0}) \\
129(\mathbf{4 9}) \\
115(\mathbf{1 8})\end{array}$ & $\mathrm{n} / \mathrm{a}$ & $\mathrm{n} / \mathrm{a}$ \\
\hline 19 & 25.894 & $\begin{array}{l}\text { 4,4'-dimethyl- } \\
{\left[2,2^{\prime} \text {-binaphthalen]-x-ol }{ }^{\mathrm{c}}\right.}\end{array}$ & $\begin{array}{c}298.1358 \\
\mathrm{C}_{22} \mathrm{H}_{18} \mathrm{O}\end{array}$ & $\begin{array}{c}298(\mathbf{7 8}) \\
281(\mathbf{1 0 0}) \\
252(\mathbf{2 3}) \\
239(\mathbf{2 1}) \\
155(\mathbf{3 2}) \\
127(\mathbf{2 1}) \\
115(\mathbf{1 7}) \\
76(\mathbf{1 0})\end{array}$ & $\mathrm{n} / \mathrm{a}$ & $\mathrm{n} / \mathrm{a}$ \\
\hline 20 & 26.179 & $\begin{array}{l}\text { 4'-methyl-[1,1'-binaphthalene] } \\
\text {-4-carbaldehyde }{ }^{\mathrm{c}}\end{array}$ & $\begin{array}{c}296.1201 \\
\mathrm{C}_{22} \mathrm{H}_{16} \mathrm{O}\end{array}$ & $\begin{array}{c}296(\mathbf{8}) \\
280(\mathbf{1 0 0}) \\
265(\mathbf{2 2}) \\
252(\mathbf{1 3}) \\
152(\mathbf{3 0}) \\
138(\mathbf{1 6}) \\
126(\mathbf{1 3}) \\
115(\mathbf{5})\end{array}$ & $\mathrm{n} / \mathrm{a}$ & $\mathrm{n} / \mathrm{a}$ \\
\hline
\end{tabular}




\begin{tabular}{|c|c|c|c|c|c|c|}
\hline 21 & 26.384 & $\begin{array}{l}\text { 4,4'-bis(hydroxymethyl)- } \\
{\left[2,2^{\prime} \text {-binaphthalene]-x, } x^{\prime} \text {-diol }\right.}\end{array}$ & $\begin{array}{l}346.1205 \\
\mathrm{C}_{22} \mathrm{H}_{18} \mathrm{O}_{4}\end{array}$ & $\begin{array}{c}346(\mathbf{4 2}) \\
296(\mathbf{8}) \\
162(\mathbf{8 6}) \\
141(\mathbf{1 0 0}) \\
127(\mathbf{1 7}) \\
115(\mathbf{3 5}) \\
91(\mathbf{1 8}) \\
77(\mathbf{8})\end{array}$ & $\mathrm{n} / \mathrm{a}$ & $\mathrm{n} / \mathrm{a}$ \\
\hline 22 & 26.457 & $\begin{array}{l}\text { 4'-(hydroxymethyl)- } \\
\text { [1,1'-binaphthalene] } \\
\text {-4-carbaldehyde }\end{array}$ & $\begin{array}{c}312.115 \\
\mathrm{C}_{22} \mathrm{H}_{16} \mathrm{O}_{2}\end{array}$ & $\begin{array}{c}312(\mathbf{2 7}) \\
267(\mathbf{6}) \\
155(\mathbf{3 1}) \\
141(\mathbf{1 0 0}) \\
127(\mathbf{2 1}) \\
115(\mathbf{1 9})\end{array}$ & $\mathrm{n} / \mathrm{a}$ & $\mathrm{n} / \mathrm{a}$ \\
\hline
\end{tabular}

${ }^{\mathrm{a}}$ Identified by the corresponding reference standard; ${ }^{\mathrm{b}}$ Proposed according to NIST library analysis; ${ }^{\mathrm{C}}$ Proposed according to the Mass spectrum; ${ }^{\mathrm{d}}$ No suggestions, ${ }^{\mathrm{e}}$ Relative abundance.

1-methylnaphthalene in the dry air environment.

In order to further understand if the $\mathrm{OH}$ group from water in the reaction environment would promote the generation of oxygenated products, moisturised air was used in the UV irradiation. Similar products were observed except that the yield of 1-naphthoic acid, 1-naphthalenemethanol and phthalic acid increased. The increase of phthalic acid is not surprising because the water in the reaction environment could act as an $\mathrm{OH}$ donor to promote the oxidation of the naphthalene skeleton, which is in agreement with results from a previous study on UV photo-oxidation of the same material dissolved in seawater [14]. However, more photo-oxidation products were observed in this study compared to the photo-oxidation of 1-methylnaphthalene in seawater. This suggests a different and more complex photo-oxidation transformation pathway of $1-\mathrm{MN}$ in the moisturised air environment.

As shown from the results above, in UV promoted photo-oxidation processes, oxygen may play an important role as either a precursor of the hydroxy or superoxo radicals. However, it is not clear how a dimer was formed in the presence of dry air in the photo-oxidation process of airborne 1-methylnaphthalene. Therefore, an experiment using an inert gas environment was conducted to investigate the transformation of 1-methylnaphthalene under UV radiation using helium or argon gas in the reaction chamber. Under this reaction environment, it was found that only three peaks, peak 1,2 and 7 were observed in the first product zone of the extracted mixture. In the second product zone, a new peak with a retention time of 24.8 min appeared (peak 14, Figure 3(b)). While peak 15 increased, peak 16 decreased, all other peaks were absent in the inert reaction environments (Figure 3(b)). The mass spectrum of the new peak, peak 14 (Figure 3(c)), suggested that it might be another dimeric product based on the NIST library analysis (Table 2). However, the actual structure of peak 14 in Fig- ure 3(b) was not confirmed due to the lack of standards. The yield increase of peak 15 in the inert reaction environment further demonstrated the formation of dimer products observed in the presence of air. Three commercially available dimers of 1-methylnaphthalene, namely 2,2'-dimethyl-1,1'-binaphthalene, 9,10-dimethyltriptycene (Sigma Aldrich rare chemical library, number T330272) and an Aldrich compound (rare chemical library) number T206571 were purchased to identify these two unknown dimers produced in the experiments. However, none of them matched the retention times of the dimers formed in the experiments. Nevertheless, the parent $\mathrm{m} / \mathrm{z} 282$ and fragment $\mathrm{m} / \mathrm{z} 141$ of their mass spectra might be enough to verify that they are dimers, which is important in that it indicates a significantly different transformation pathway that was not observed previously.

It was anticipated that the oxygenated compounds would not be generated from the photo-oxidation under the inert gas environments. However, two of the side chain oxygenated compounds, phthalic anhydride and 1-naphthaldehyde represented by peak 1 and 7, respectively, were still observed in both the helium and argon gas environments, though at significantly reduced levels compared to the dry air environment. The small quantity of oxygenated products observed in this case could be attributed to the small amount of water present in the helium or argon gas as an impurity, and its involvement in oxygenation reactions. This might also explain the observation of peak 16, a possible oxygenated dimer product, in the absence of air. However, the disappearance of the alcohol and acid products, on the other hand, could demonstrate that the lack of oxygen in the air in the system significantly reduced the formation of further oxygenated compounds.

\subsection{Transformation Pathways}

Aphoto-oxidation mechanism for 1-methylnaphthalene in 
atmospheric conditions was previously proposed for the formation of ring-opened transformation products including (E)-3-(2-acetylphenyl)acrylaldehyde and the major dicarbonyl products through an initial reaction with an $\mathrm{OH}$ radical followed by the reaction with oxygen and $\mathrm{NO}$ or $\mathrm{RO}_{2}$ radicals [17]. The ring-retained products resulted from side chain oxidations. Another photo-transformation pathway of 1-methylnaphthalene in water was proposed as the formation of the reaction products through reaction of 1-methylnaphthalene with excited oxygen followed by a ring opening process under UV irradiation and then by reaction with another oxygen molecule to form ring-opened products or ring-cutting productssuch as 3-methyl-1(3H)-isobenzofuranone [14]. Both mechanisms can be applied to interpret the formation of ring-opened or ring-cutting products observed in this study. In summary, 1-methynapthalene first went through an initial reaction with $\mathrm{OH}$ radical under UV radiation to form either 1-methylnaphthyl radical or hydroxyl 1-methylnaphthyl radical. The 1-methylnaphthyl radical would thereby pick up a molecule of oxygen to form the corresponding methylnaphthalene peroxy radical. Subsequent transformations may occur via reactions with $\mathrm{NO}, \mathrm{NO}_{2}, \mathrm{HO}_{2}$ radicals or another methylnaphthalene peroxy radical to give the side chain oxygenated compounds, 1-naphthaldehyde, 1-naphthoic acid and 1-naphthylmethanol. The hydroxyl 1-methylnaphthyl radical may also pick up a molecular oxygen and lose a carbon atom from the benzene ring to form ring-retained or ring-opened oxygenated compounds such as phthalic anhydride,3-methyl-1(3H)-isobenzofuranone, and 3,Xdimethyl-1(3H)-isobenzofuranone.

However, the formation of dimeric products likely indicates a different photo-oxidation mechanism. To the best of our knowledge, no mechanism has yet been proposed for the formation of dimers and oxygenated dimer products. According to the findings in this study, it is reasonable to believe that radical reactions would be the initial pathway for UV photo-oxidation of 1-methylnaphthalene in the presence of air. Either excited oxygen or hydroxyl radical mediated the formation of two types of methylnaphthalene-based radicals. We therefore propose a plausible pathway for the formation of dimers under photo oxidation of 1-methynaphthalene (Figure 4(a)). The 1-methylnaphthyl radical would add or rearrange with another 1-methylnaphthyl radical to form either a single or double carbon-carbon bond dimers (M.W. 282 or M.W. 280). Alternatively, even in the presence of air, the lack of enough oxygen in the small reaction chamber or a slow oxygenation reaction rate in the dry air, might allow enough time for the rearrangements of the incipient radicals to form dimers. However, in the (a)

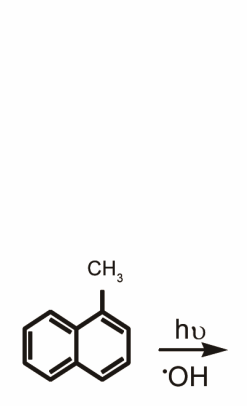

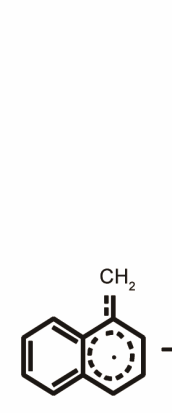

1

\section{C - C binding}

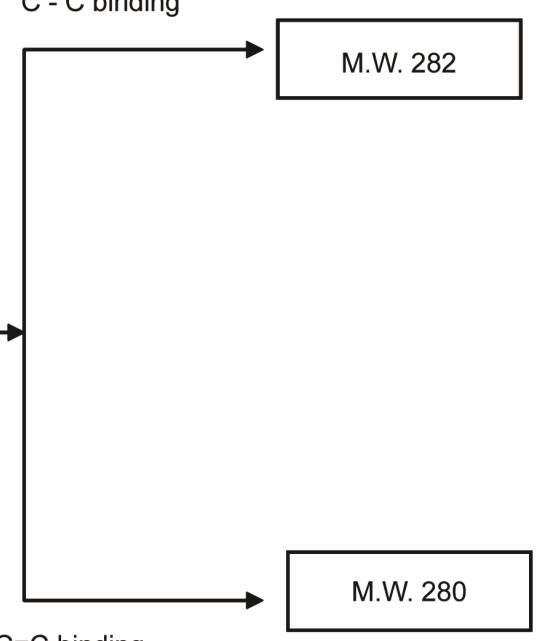

$\mathrm{C}=\mathrm{C}$ binding

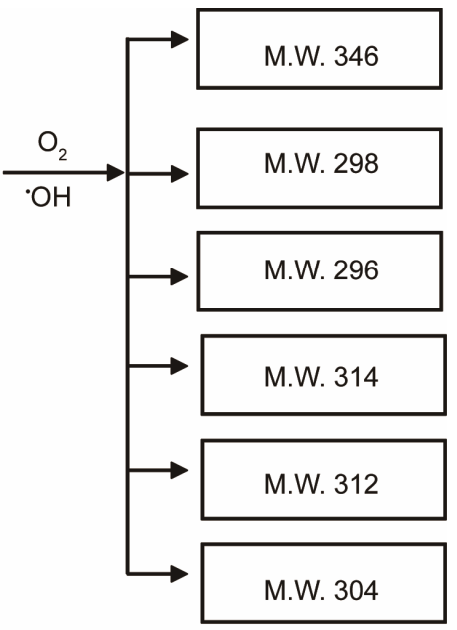

(b)
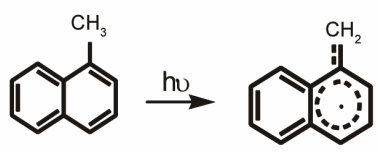

C - C binding

M.W. 282

Figure 4. Possible transformation pathways of 1-MN under UV light. 
presence of oxygen, the dimers (M.W. 282) could further pick up a molecular oxygen or another hydroxyl radical to form oxygenated dimeric products with a molecular weight of 296, 298, 304, 312, 314 and 346 (Figure 4(a)). The possible oxygenated dimeric products found in the current study support this pathway and also demonstrate that the dimers can be further oxygenated even in the presence of a small amount of oxygen. In contrast, under the inert gas reaction environment, dimers were the primary reaction products. Therefore, the transformation should mainly follow a photolysis pathway in the absence of oxygen. Alternatively, the photolysis of 1-methylnapthaleneat the methyl side chain under the UV radiation could form a 1-methylnaphthyl radical (Figure 4(b)). The subsequent addition or rearrangement of the 1-methylnaphthyl radical with each other would result in the formation of the single carbon-carbon bond dimers (M.W. 282).

\subsection{Implications for the Contaminants Research}

When the primary contaminants transform in the environment through the reactions with environmental factors, they may form similarly or even more mobile, persistent, or toxic transformation products than the parent compound [18]. The interactions with each other among the primary contaminants would further result in additive or potentially even synergistic mixture effects in formation of highly variable and unknown transformation products which are concerned in human exposure. Moreover, the majority of transformation products have most likely not even been identified yet while some of the resulting transformation products are known to be more abundant in the environment than their parent compounds $[19,20]$. In order to accurately evaluate the exposure risk of parent compounds in the environment, therefore, it is necessary to comprehensively understand the transformation products, which is helpful to the contaminants research.

From the discussion above, we can see that 1-methylnaphthalene can be transformed by UV light to more than 21 products. Among those transformation products, phthalic anhydride is a volatile chemical that can have an irritative effect on mucous membranes and the skin [21-23], and repeated exposure may cause allergic skin rash, rhinitis, bronchitis and asthma [24]. It is also a major compound of concern in air quality. 1-naphthaldehyde is more volatile than 1-methylnaphthalene. In addition, 1-naphthaldehyde is more toxic than the parent compound and commonly found in diesel engine exhaust [25]; therefore the formation of this compound would increase the complexity of its sources. 1-Hydroxymethylnaphthalene, 2-acetylbenzoic acid and naphthoic acid are more water soluble compounds compared to the parent compound, 1-methylnaphthalene. Two-ring naphthoic acids were previously reported commonly from biodegradation of three-ring (e.g., phenanthrene and anthracene) and four-ring (pyrene and chrysene) PAHs in soils, sediments or goethite [26-28]. However, this study first demonstrated that this low-molecular-weight organic acid can be transformed from 1-methylnaphthalene under UV light in the presence of air environment, implying that the photo-oxidation in the environment could result in similar transformation products to those from the biodegradation process.

In addition to the one-ring and two-ring transformation products, this is the first study to show 1-methylnaphthalene dimerizing under environmental conditions. Compared to earlier studies on the transformation of 1-methylnaphthalene in either water or air in which no dimerization was detected, this study found two dimers and eight possible oxygenated dimeric products. It is clear that methyl naphthalene can be transformed into a larger number of products. This work shows that it is important to continue to investigate such transformations in order to better understand any risk arising from the presence of these compounds in the environment.

The presence of more than 21 transformation products observed in this study indicates that the formation of transformation products in the environment can add further complexity to risk assessment. Those transformation products may contribute to the risk posed by the parent compound. The three major compounds, 1-naphthaldehyde, 1-hydroxymethylnaphthalene, and naphthoic acid, with a yield of as high as around $10 \%$ each in the transformation of 1-methylnaphthalene, are either more volatile or water soluble than the parent compound. It has been reported that these alkyl side chain hydroxylation products were more toxic than the parent methylnaphthalenes [23]. Dimers and oxygenated dimeric products could be more persistent and toxic due to more rings. Importantly, those transformation products can also add exposure complexity of 1-methylnaphthalene as a mixture in the environment. The degradation rate of a chemical is a very important parameter to evaluate its behavior in the environment. We observed that over all, about $40 \%$ of 1 -methylnaphthalene was degraded within 48 hours (Figure 5). It can be seen, in Figure 5, that the degradation curve reached a flat at about 30 hours of UV exposure. The flat range of the curve could be attributed to the blockage of UV-light by the transformation products deposited on the glass wall. With the degradation pattern within the first 30 hours of UV exposure, the half degradation time or half-life could be estimated to be about 38 hours. Although this estimated half degradation time of 1-methylnapthalene is longer than the lifetime of those dimethylnapthalenes reported previously [11], the 


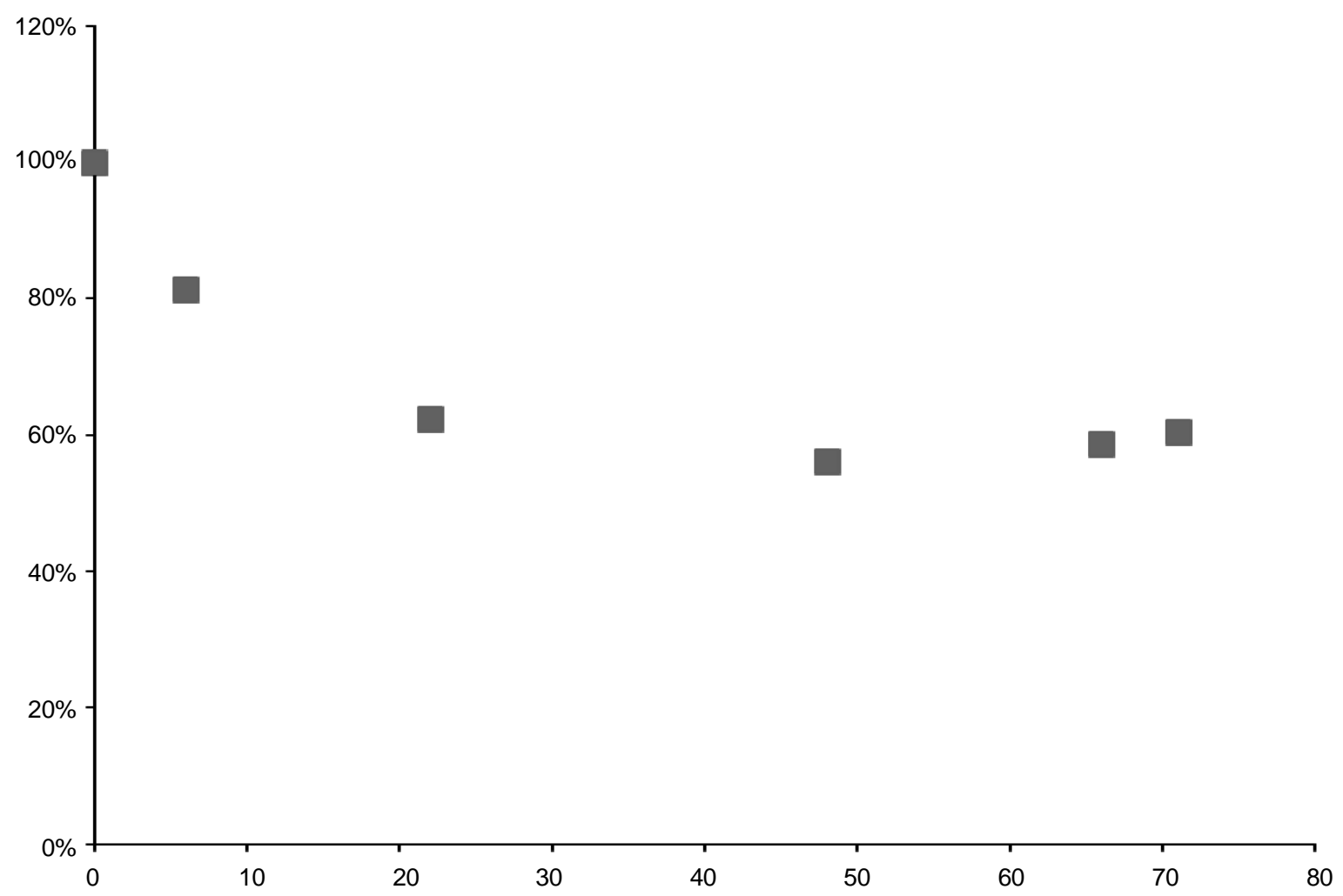

Figure 5. The relationship of the remaining 1-methylnaphthalene in degradation with the exposure time of UV light.

result of this study indicates that this light-molecular-weight PAH is able to be transformed in the air environment.

The results of the current study are only subject to UV light induced degradation products. The photo-oxidative processes observed in this study lead to the formation of oxygenated products that are more polar and consequently, more water soluble than the parent compounds. However, the formation of dimers and oxidized dimeric products under the same environmental conditions indicates that it can yield more complex transformation products in the environment. The presence of dimers and oxidized dimers suggests that a mixture of contaminants could lead to a complex mixture of transformation products. Regardless of the type of transformation pathway, the results from the present study demonstrate an important fact that 1-methylnapthalene can be transformed to as many as 21 products in the presence of air. Although some of those compounds have not yet been identified in the present study, their mass spectra indicate that most of them are oxygenated compounds from 1-methylnaphthalene. More importantly, the formation of dimers and the possibility of further oxygenated compounds forming from the dimers were first demonstrated in this study. It reveals the complexity of photo-oxidation in the presence of air, which indicates the potential sources of secondary pollutants in the environment. Further study is secured to confirm the identity of some of the dimers and their oxygenated compounds. These compounds need to be characterized in order to better understand any potential risks. The results of this study indicate the importance of understanding transformation of environmental pollutants in contaminants research. Methylnaphthalene is one of many PAH compounds that can be found in both outdoor and indoor environments, therefore, the fate and transformation products of such environmental contaminants should be examined.

\section{Conclusion}

This study has revealed that 1-methylnaphthalene in the air environment was photo-transformed via reactions with oxygen and/or water primarily to ring-opened products, such as (E)-3-(2-acetylphenyl)acrylaldehyde, and side chain oxidized compounds, such as 1-naphthaldehyde, 1-naphthoic acid and 1-naphthylmethanol. Significant dimerization occurred when the reaction was carried out in the inert atmosphere. Dimers and their oxygenated products in the presence of oxygen were first observed in this study. A radical reaction mechanism was proposed for the formation of dimers and oxygenated dimers. The 21 transformation products resulted from only one com- 
pound, 1-methylnaphthalene, under UV radiation indicates the importance of further study on the environmental fate of airborne contaminants and the impacts of transformation products to the environment.

\section{Acknowledgements}

This project was financially supported by the Canadian government under the Chemicals Management Plan (CMP).

\section{REFERENCES}

[1] P. T. Williams, K. D. Bartle and G. E. Andrews, "The Relation between Polycyclic Aromatic Compounds in Diesel Fuels and Exhaust Particulates," Fuel, Vol. 65, No. 8, 1986, pp. 1150-1158. doi:10.1016/0016-2361(86)90184-5

[2] P. F. Nelson, "Combustion-Generated Polycyclic Aromatic Hydrocarbons in Diesel Exhaust Emissions," Fuel, Vol. 68, No. 3, 1989, pp. 283-286. doi:10.1016/0016-2361(89)90088-4

[3] B. Zielinska, J. C. Sagebiel, G. Harshfield, A. W. Gertler and W. R. Pierson, "Volatile Organic Compounds up to $\mathrm{C}_{20}$ Emitted from Motor Vehicles; Measurement Methods," Atmospheric Environment, Vol. 30, No. 12, 1996. pp. 2269-2286. doi:10.1016/1352-2310(95)00116-6

[4] L. C. Marr, T. W. Kirchstetter, R. A. Harley, A. H. Miguel, S. V. Heringand and S. K. Hammond, "Characterization of Polycyclic Aromatic Hydrocarbons in Motor Vehicle Fuels and Exhaust Emissions," Environmental Science \& Technology, Vol. 33, No. 18, 1999, pp. 30913099. doi:10.1021/es9812271

[5] P. J. Tancell, M. M. Rhead, R. D. Pemberton and J. Braven, "Survival of Polycyclic Aromatic Hydrocarbons during Diesel Combustion," Environmental Science \& Technology, Vol. 29, No. 11, 1995, pp. 2871-2876. doi:10.1021/es00011a025

[6] T. J. Truex, J. M. Norbeck, M. R. Smith, J. Arey, N. Kado and B. Okamoto, "Evaluation of Factors That Affect Diesel Exhaust Toxicity," Contract No. 94-312, Final Report to California Air Resources Board, Sacramento, 1998, 287 p.

[7] F. Reisen and J. Arey, "Atmospheric Reactions Influence Seasonal PAH and Nitro-PAH Concentrations in the Los Angeles Basin," Environmental Science \& Technology, Vol. 39, No. 1, 2005, pp. 64-73. doi:10.1021/es0354541

[8] J. J. Schauer, M. J. Kleeman, G. R. Cass and B. R. T. Simoneit, "Measurement of Emissions from Air Pollution Sources. 2. C-1 through C-30 Organic Compounds from Medium Duty Diesel Trucks," Environmental Science \& Technology, Vol. 33, No. 10, 1999, pp. 1578-1587. doi:10.1021/es980081n

[9] J. J. Schauer, M. J. Kleeman, G. R. Cass and B. R. T. Simoneit, "Measurement of Emissions from Air Pollution Sources. 3. C-1-C-29 Organic Compounds from Fireplace Combustion of Wood," Environmental Science \& Technology, Vol. 35, No. 9, 2001, pp. 1716-1728.

\section{doi:10.1021/es001331e}

[10] F. Wania and D. Mackay, "Tracking the Distribution of Persistent Organic Pollutants," Environmental Science \& Technology, Vol. 30, No. 9, 1996, pp. 390A-396A. doi: $10.1021 / \mathrm{es} 962399 \mathrm{q}$

[11] P. T. Phousongphouang and J. Arey, "Rate Constants for the Gas-Phase Reactions of a Series of Alkylnaphthalenes with the OH Radical," Environmental Science \& Technology, Vol. 36, No. 9, 2002, pp. 1947-1952. doi:10.1021/es011434c

[12] L. Wang, R. Atkinson and J. Arey, "Dicarbonyl Products of the OH Radical-Initiated Reactions of Naphthalene and the C1- and C2-Alkylnaphthalenes," Environmental Science \& Technology, Vol. 41, No. 8, 2007, pp. 2803-2810. doi:10.1021/es0628102

[13] N. Nishino, J. Arey and R. Atkinson, "Yields of Glyoxal and Ring-Cleavage Co-Products from the $\mathrm{OH}$ RadicalInitiated Reactions of Naphthalene and Selected Alkylnaphthalenes," Environmental Science \& Technology, Vol. 43, No. 22, 2009, pp. 8554-8560. doi:10.1021/es902018v

[14] M. G. Ehrhardt, M. C.Bicego and R. R. Weber, "PhotoOxidation of 1-Methylnaphthalene Dissolved in Seawater and Exposed to Sunlight under Quasi-Environmental Conditions," Journal of Photochemistry and Photobiology A, Vol. 108, No. 2-3, 1997, pp. 253-259. doi:10.1016/S1010-6030(97)00079-8

[15] R. Atkinson, "Atmospheric Chemistry of VOCs and $\mathrm{NO}_{x}$," Atmospheric Environment, Vol. 34, No. 12-14, 2000, pp. 2063-2101. doi:10.1016/S1352-2310(99)00460-4

[16] F. Reisen, S. Wheeler and J. Arey, "Methyl- and Dimethyl-/Ethyl-Nitronaphthalenes Measured in Ambient Air in Southern California," Atmospheric Environment, Vol. 37, No. 26, 2003, pp. 3653-3657. doi:10.1016/S1352-2310(03)00469-2

[17] A. W. H. Chan, K. E. Kautzman, P. S. Chhabra, J. D. Surratt, M. N. Chan, J. D. Crounse, A. Kurten, P. O. Wennberg, R. C. Flagan and J. H. Seinfeld, "Secondary Organic Aerosol Formation from Photooxidation of Naphthalene and Alkylnaphthalenes: Implications for Oxidation of Intermediate Volatility Organic Compounds (IVOCs)," Atmospheric Chemistry and Physics, Vol. 9, 2009, pp. 3049-3060. doi:10.5194/acp-9-3049-2009

[18] C. Tixier, M. Sancelme, E. Bonnemoy, A. Cuer and H. Veschambre, "Degradation Products of a Phenylurea Herbicide, Diuron: Synthesis, Ecotoxicity, and Biotransformation," Environmental Toxicology and Chemistry, Vol. 20, No. 7, 2001, pp. 1381-1389. doi:10.1002/etc.5620200701

[19] A. B. A. Boxall, C. J. Sinclair, K. Fenner, D. Kolpin and S. J. Maud, "When Synthetic Chemicals Degrade in the Environment," Environmental Science \& Technology, Vol. 38, No. 19, 2004, pp. 368A-375A. doi:10.1021/es $040624 \mathrm{v}$

[20] A. B. A. Boxall, "Transformation Products of Synthetic Chemicals in the Environment," Berlin/Heidelberg, Springer, 2009. 
[21] M. Pakarinen, M. Koivuluhta, N. Kalkkinen, H. Keskinen, H. Nordman, T. Estlander, O. Tupasela, R. Jolanki, A. I. Lauerma, P. Pfäffli and H. Alenius, "Phthalic Anhydride Allergy: Development and Characterization of Optimized Hapten-Carrier Conjugates for Improved Diagnosis," Allergy, Vol. 57, No. 10, 2002, pp. 894-899. doi:10.1034/j.1398-9995.2002.23579.x

[22] M. Wernfors, J. Nielsen, A. Schütz and S. Skerfving, "Phthalic Anhydride-Induced Occupational Asthma," International Archives of Allergy and Applied Immunology, Vol. 79, No. 1, 1986, pp. 77-82. doi:10.1159/000233946

[23] C. E. Cerniglia, J. P. Freeman, J. R. Althaus and C. van Baalen, "Metabolism and Toxicity of 1-Methylnaphthalene and 2-Methylnaphthalene and Their Derivatives in Cyanobacteria," Archives of Microbiology, Vol. 136, No. 3, 1983, pp. 177-183. doi:10.1007/BF00409840

[24] P. Pirkko, "Phthalic Acid Excretion as an Indicator of Exposure to Phthalic Anhydride in the Work Atmosphere," International Archives of Occupational Environmental Health, Vol. 58, No. 3, 1986, pp. 209-216.

\section{doi:10.1007/BF00432103}

[25] R. Barbella, A. Ciajolo and A. D'Anna, "The Emission of Heavy Hydrocarbons from a Dieselengine and a Spray Flame," Fuel, Vol. 68, No. 6, 1989, pp. 690-695. doi:10.1016/0016-2361(89)90205-6

[26] J. B. Sutherland, F. Rafii, A. A. Khan and C. E. Cerniglia, "Mechanisms of Polycyclic Aromatic Hydrocarbon Degradation," In: L. Y. Young and C. E. Cerniglia, Eds., Microbial Transformation and Degradation of Toxic Organic Chemicals, Wiley-Liss, New York, 1995.

[27] K. L. Shuttleworth and C. E. Cerniglia, "Environmental Aspects of PAH Biodegradation," Applied Biochemistry and Biotechnology, Vol. 54, No. 1-3, 1995, pp. 291-302. doi:10.1007/BF02787927

[28] K. Hanna and J.-K. Boily, "Sorption of Two Naphthoic Acids to Goethite Surface under Flow through Conditions," Environmental Science \& Technology, Vol. 44, No. 23, 2010, pp. 8863-8869. doi:10.1021/es102903n 